\title{
Ecological-Economic Model of Managing Recreational Potential of the Sea Coastal Zone
}

\author{
I. E. Timchenko*, I. K. Ivashchenko, E. M. Igumnova, Yu. I. Nikiforov \\ Marine Hydrophysical Institute, Russian Academy of Sciences, Sevastopol, Russian Federation \\ *e-mail: timchenko.syst.analysis@mhi-ras.ru
}

\begin{abstract}
Adaptive model of managing consumption and reproduction of the recreational potential in the sea coastal zone is proposed. The recreational potential is assessed based on the nature and climate features, development of a resort infrastructure, quality of recreation services and level of the coastal zone pollution. The concepts of the recreational resource concentration and the resource capacity of a recreational unit which characterize its recreational potential are introduced. Constructed is the ecological-economic model of the recreational resource consumption consisting of the economic subsystem (rendering of recreational services) and the block of managing the environmental activity which controls pollution of the recreational and coastal areas. The model equations are constructed by the method of adaptive balance of causes including the logical management agents. Such an approach is applied in the model developing intended to monitor dynamics of the recreational capacity of the South Crimea coastal region. The aim of the study is to construct the spatial-temporal scenarios of the ecological and economic processes which characterize response of the model managing recreational services to seasonal variability of the recreational potential of the sea coastal zone. The scenarios of the modeled ecological and economic processes are given. To initiate the spatial variant of the model, a part of the South Crimea coast supplied with the digital map showing average estimates of its recreational attractiveness is used. The model response to seasonal changes in the recreational potential was investigated. It is shown that in order to maintain the quality of recreational services, it is necessary to manage the balance between the rates of consumption and reproduction of the recreational resource, which characterizes the recreational capacity of the sea coastal zone.
\end{abstract}

Keywords: ecological and economic system, adaptive balance of causes, consumption and reproduction of recreational resource, seasonal variability, marine pollution, recreational capacity of the coastal zone.

Acknowledgements: the investigation is carried out within the framework of the state task on the theme № 0827-214-0010 "Complex interdisciplinary investigations of the oceanologic processes conditioning functioning and evolution of the Black and Azov seas' ecosystems based on the modern methods for controlling the marine environment condition, and the hydraulic technologies”. The model is developed and the computing experiments are performed within the framework of the scientific project of the Russian Fund of Fundamental Investigations and the Sevastopol Administration № 18-47-920001 "Study of the principles for constructing adaptive models of the ecological-economic systems and digital informational technologies for managing the scenarios of sustainable development of the natural and economical complexes in the Seavastopol region”.

For citation: Timchenko, I.E., Ivashchenko, I.K., Igumnova, E.M. and Nikiforov, Yu.I., 2018. Ecological-Economic Model of Managing Recreational Potential of the Sea Coastal Zone. Physical Oceanography, [e-journal] 25(5), pp. 420-432. doi:10.22449/1573-160X-2018-5-420-432.

DOI: $10.22449 / 1573-160 \mathrm{X}-2018-4-420-432$

(C) 2018, I. E. Timchenko, I. K. Ivashchenko, E. M. Igumnova, Yu. I. Nikiforov

(C) 2018, Physical Oceanography

Introduction. Management of recreational resource consumption and reproduction is one of the main purposes of ecological economics of the coast - sea natural-economic systems [1-15]. As is known, for the sustainable development of such systems a reasonable compromise between the obtaining economic benefits from the natural resource consumption and the saving normal ecological state of PHYSICAL OCEANOGRAPHY VOL. 25 ISS. 5 (2018) 
the environment is needed $[8,12]$. Therefore, numerical models and digital information technologies are created for managing the scenarios of economic and ecological processes of recreation, which allow finding such compromise solutions $[16,17]$.

Among the consumed natural resources of the sea coastal zone recreational potential, which is used by recreation objects for the rest and health improvement of people, plays an important role. Recreational potential means that a recreation object has recreational resource and recreational capacity which are formed under effect of natural-climatic, infrastructural and service opportunities for the provision of recreational services. The coastal marine environment is one of the most important components of the object recreational attractiveness. With the growth of attractiveness the demand for services in this area increases, but the possibilities of providing quality services are always limited by the ultimate recreational capacity of certain sections of the sea coastal zone.

One of the possible ways to create ecological-economic models and technologies for managing recreational potential is to apply the adaptive balance of causes method [18]. An example of the use of this method is the work [17], in which a rational balance between the economic benefits of industrial waste disposal into the sea and the preservation of the marine environment ecological state is based on the system management according to three criteria: the economic profitability of marine bioresource consumption, pollution level and marine environment biodiversity index.

In the present study, a similar approach was applied when creating a model for monitoring the recreational capacity dynamics of the Crimean territory section adjacent to the Southern Coast marine area. The purpose of the work was the construction of such spatial-temporal scenarios of ecological and economic processes that characterize a response of the model for managing the volume of recreational services to the seasonal variability of the sea coastal zone recreational potential.

Cause-effect relationships in the conceptual model of the sea coastal zone recreational resource consumption and reproduction. In order to construct the recreational potential conceptual model, we formulate certain definitions. Recreational potential is formed by a sustainable system of environmental factors, infrastructure and service useful for application as a recreational resource. In this study we will consider the recreational resource as a quantitative assessment of the recreational potential of recreation object. This assessment can be represented in the form of weighted sum of factors affecting it expressed in dimensionless units (points). Formally, the number of points related to the unit area of the recreation object can be considered as the concentration of the recreational resource $R R$, with which a certain number of potential consumers of recreational services is associated.

We call a recreational service a set of activities defined by nature, volume, time and quality, which are aimed at recreation and health improvement of a subject of recreation (recreationist). The performance of services is associated with the consumption of a recreational resource and a decrease in its $R R$ concentration. Recreational resource consumption rate is the number of provided recreational services per unit of time, which depends on the demand for services. In parallel with the resource 
consumption, the process of its reproduction is developing at the recreation object. For each object there is a maximum possible rate of recreational resource consumption, which cannot exceed the rate of its reproduction without reducing the quality of services. Therefore, for the recreation object, in addition to the concentration of the recreational resource $R R$, it is advisable to use another (integral) characteristic of the balance of these rates: an object recreational capacity $R C$.

We determine the recreational capacity of recreation object as the maximum possible number of provided recreational services in the time interval $(0, t)$, which maintains the balance of recreational resource consumption and reproduction rates. The recreational capacity maximum value corresponds to the maximum load on the recreational object at which the resource reproduction rate begins to lag behind the rate of its consumption. The difference in the recreational resource consumption and reproduction volume at $(0, t)$ time interval is a shortage of recreational services supply relative to the existing demand for them. Therefore, for managing the recreational potential of recreation territory (object) it is necessary to use the assessments of both resource concentration $R R$ and recreational capacity $R C$.

The provision of recreational services is inevitably associated with the events that negatively affect the concentration of recreational resource. They include: contamination of territories, facilities and the beach area with rubbish, bacterial contamination of the coastal marine environment and a decline in the service quality for recreants. Therefore, in the model of ecological-economic system of recreation, the volume of performed recreational services can negatively affect all the factors that form the recreational attractiveness of the resort. In this study, a common index (a level of environmental pollution $P L$ ) was applied for taking this effect into account.

The definitions introduced above were used to construct a cause-effect relationship scheme that formed the basis of the conceptual model for managing the recreational potential of the sea coastal zone recreation object. This diagram is shown in Fig. 1. Designations in the diagram are dimensionless indices of the model variables expressed in units of average values of the modeled processes. The recreational resource index $R R$ is formed under the impact of environmental indices $E N$, infrastructure and service maintenance $I S$, as well as the ones of environmental safety of the resort zone territory and sea area $E S$. The recreational attractiveness of the resort depends on them and, consequently, the demand $D$ for the provision of recreational services. An agent of demand for recreational services $A G_{\mathrm{D}}$ compares the current value of the $R R$ index with the value of this index in the stationary (average) state of the recreation object $R R^{*}=C_{\mathrm{RR}}$ which characterizes the integral balance of recreational resource consumption and reproduction volumes. Actual volume of services $V$ is determined by management agent $A G_{\mathrm{V}}$ that compares the economic profitability of services $E F$ with the resort resource capacity $R C$.

In order to control the pollution $P L$, the imposition of penalties $T X$ (which limit the volume of recreational services $V$ ) on the economic system is provided. Accumulation of funds from the imposed penalties in a special fund $T X_{\text {acc }}$ allows one to special environment protection measures aimed at sharp decrease of pollution level. 


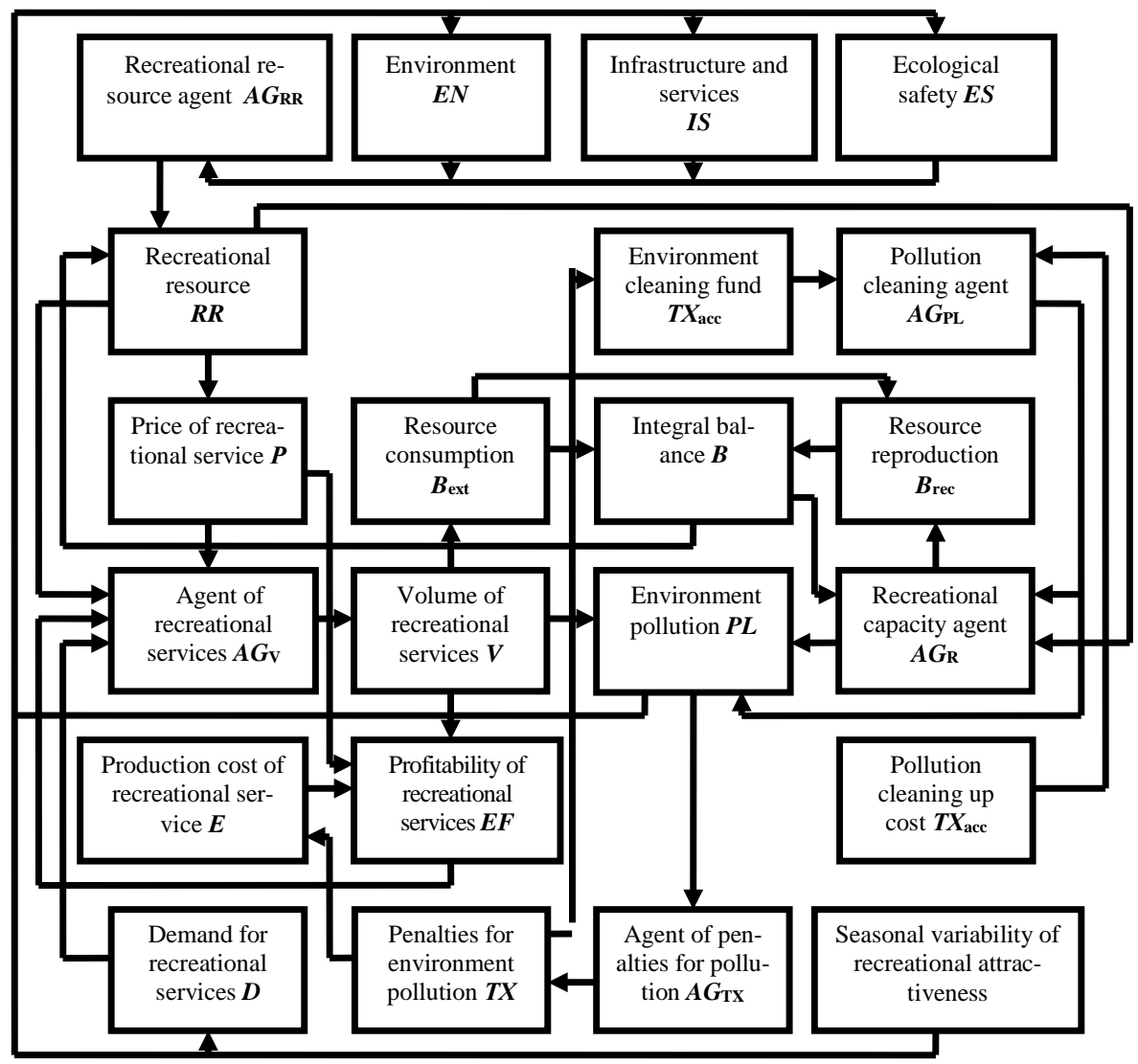

Fig. 1. Conceptual model of consumption and reproduction of the sea coastal zone resource

Equations of the model of ecological-economic system for managing the recreational resource of recreation object. When constructing the equations the Adaptive Balance of Causes method (ABC-method) $[6,18]$ was applied. Its essence is the following: an assumption about the existence of a stable stationary (equilibrium) state of a system of processes $u_{i}$, interrelated with cause-effect dependencies $u_{i}=a_{i j} u_{j}$, where $a_{i j}$ are the effect coefficients, is introduced. In this condition the model variables take their statistical average values $u_{i}=C_{i}$. External effects $A_{i}$ shift the system from the equilibrium state into the new ones in which the material balances of processes interaction between themselves and with external effects are preserved. Let, for example, a variable be under the positive effect of $m$ variables $u_{k}$ and the negative effect of $n-m$ variables $u_{l}$. Then the material balance of the processes interaction can be represented as

$$
u_{i}=C_{i}+\sum_{k=1}^{m} a_{i k}\left(u_{k}-C_{k}\right)-\sum_{l-1}^{n-m} a_{i l}\left(u_{l}-C_{l}\right)+A_{i},
$$


where $a_{i k}$ and $a_{i l}$ are the coefficients of positive and negative effects, respectively.

In $[6,18]$ it is shown that for keeping the balances (1) it is advisable to use modular equations of the $A B C$-method of the following form:

$$
\frac{d u_{i}}{d t}=2 r_{i} u_{i}\left[C_{i}-\left(u_{i}-\sum_{k=1}^{m} a_{i k}\left(u_{k}-C_{k}\right)+\sum_{l=1}^{n-m} a_{i l}\left(u_{l}-C_{l}\right)-A_{i}\right)\right],
$$

where $r_{i}$ are the specific rates of $u_{l}$ functions changes. Due to the second order negative feedback between the variables and the rates of their change, such a system of equations provides the adaptation of variables to each other and to external effects. At the same time, an additional condition is put - the effect does not take the variables beyond the specified intervals of variability $\left(0 \leq u_{i} \leq 2 C_{i}\right)$ :

$$
u_{i}=\operatorname{IF}\left\{u_{i}<0 ; 0 ; \operatorname{IF}\left[u_{i}>2 C_{i} ; 2 C_{i} ; u_{i}\right]\right\} .
$$

The problem of determining the effect coefficients $a_{i j}$ is solved in various ways. In the $A B C$-method these coefficients link the reaction products of processes interaction $u_{i}$ with the resources $u_{j}$ by ratios. Therefore, depending on the type of interactions (physical, biochemical, etc.), there are theoretical and experimental connections that serve to estimate the coefficients of effects. If at the disposal of the researcher there are time series of observations of the processes $u_{i}$ and $u_{j}$, the effect coefficients $a_{i j}$ are determined using the mutual correlation functions calculated for these series. In particular, it is possible to construct adaptive dynamic models of the effect coefficients by Kolmogorov and Kalman methods of optimal filtration [6, 18-20].

In this research we apply a new method for estimating the effect coefficients according to the normalized ratios of modeled variable average values, which was proposed in [21]. According to this method, the effect coefficients in equations (2) can be determined by the normalized ratios of average values:

$$
a_{i k}=\frac{C_{i}}{2 m} C_{k}^{-1}, \quad a_{i l}=\frac{C_{i}}{2(n-m)} C_{l}^{-1} .
$$

When constructing the model equations, the notations for the variables shown in Fig. 1 were used. We determine the sum of effects on the function $u_{i}$ in equation (3) as

$$
F\left(u_{i}\right)=\sum_{k=1}^{m} a_{i k}\left(u_{k}-C_{k}\right)-\sum_{l=1}^{n-m} a_{i l}\left(u_{l}-C_{l}\right)+A_{i} .
$$

Since all the equations of the adaptive model have the same structure, they differ only in their affecting functions. Therefore, for the system of equations formalizing the conceptual model from Fig. 1 it is sufficient just to write out the functions $F\left(u_{i}\right)(5)$. We show this on the example of equation for the recreational resource index:

$$
\frac{d R R}{d t}=2 r_{\mathrm{RR}} R R\left\{C_{\mathrm{RR}}-[R R-F(R R)]\right\},
$$




$$
F(R R)=A G_{\mathrm{RR}}(E N, I S, E S)-a_{\mathrm{RR} / \mathrm{B}} B .
$$

$A G_{\mathrm{RR}}$ agent performs the function of searching for a factor limiting the value of $R R$ index at the current time moment among the values of $E N$, IS, ES indices:

$$
\begin{aligned}
& A G_{\mathrm{RR}}(E N, I S, E S)=I F\left(M_{\mathrm{RR}}=a_{\mathrm{RR} / \mathrm{EN}} E N ; a_{\mathrm{RR} / \mathrm{EN}} E N ; 0\right)+I F\left(M_{\mathrm{RR}}=a_{\mathrm{RR} / \mathrm{IS}} I S ; a_{\mathrm{RR} / \mathrm{IS}} I S ; 0\right)+ \\
& +I F\left(M_{\mathrm{RR}}=a_{\mathrm{RR} / \mathrm{ES}} E S ; a_{\mathrm{RR} / \mathrm{ES}} E S ; 0\right), \\
& M_{\mathrm{RR}}(t)=\arg \min \left[a_{\mathrm{RR} / \mathrm{EN}} E N ; a_{\mathrm{RR} / \mathrm{IS}} I S ; a_{\mathrm{RR} / \mathrm{ES}} E S\right] .
\end{aligned}
$$

Function $B$ is determined as integral balance of consumption $B_{\text {ext }}(t)$ and reproduction $B_{\mathrm{rec}}(t)$ volumes of recreational resource at the time interval $(0 ; t)$ :

$$
B(t)=B_{\text {ext }}(t)-B_{\text {rec }}(t)=a_{\mathrm{B} / \mathrm{v}} \int_{0}^{t}[1-R(\tau)] V(\tau) \mathrm{d} \tau .
$$

It was considered that the volumes of resource consumption were proportional to the ones of provided recreational services $V(t)$. $B(t)$ function integrally takes into account the occurrence of recreational resource shortage when the volumes of its consumption exceed the recreational capacity of recreational object. The control over the shortage occurrence is provided by the function $R(\tau)$ which is an agent of recreation object resource capacity:

$$
A G_{\mathrm{R}}=R(t)=I F\left\{R R>C_{\mathrm{RR}} ; ; ; I F\left[T X_{\text {acc }}<T X_{\text {acc }}^{*} ; \exp \left(-\alpha_{\mathrm{R}} \tau\right)\right] ; R(t)+[1-R(t)]\left[1-\exp \left(-\beta_{\mathrm{R}} \tau\right)\right]\right\} \cdot
$$

The role of this agent is to monitor the deviations of $R R$ index from its average value $C_{\mathrm{RR}}$. When this index exceeds an average value, recreational resource reproduction rate is equal to the rate of its consumption, the function $R(\tau)=1$ and recreational capacity shortage is absent. Otherwise, reproduction rate lags behind the one of consumption and, according to formula (9), recreational resource shortage exponentially increases with the parameter $\alpha_{R}$.

The second logical condition in this makes it possible to turn on the regime of environmental actions, when the value of fund for clearing the object territory and the surrounding marine environment from pollution $T X_{\text {acc }}$ will exceed the specified value $T X_{\text {acc }}^{*}$. In this regime reproduction rate exponentially increases with $\beta_{\mathrm{R}}$ parameter.

In the equations for recreational resource factors the negative impact on them of contamination level of the object and the surrounding marine environment $P L$ was taken into account:

$$
F(E N)=-a_{\mathrm{EN} / \mathrm{PL}}\left(P L-C_{\mathrm{PL}}\right) ; F(I S)=-a_{\mathrm{IS} / \mathrm{PL}}\left(P L-C_{\mathrm{PL}}\right) ; F(E S)=-a_{\mathrm{ES} / \mathrm{PL}}\left(P L-C_{\mathrm{PL}}\right) \text {. }
$$

Environment pollution level was affected by the volumes of recreational services $V$, the agent $A G_{\mathrm{PL} / \mathrm{RR}}(P L, R R)$ which monitored the decrease of recreational resource index below the average value $C_{\mathrm{RR}}$ and the agent of environment protection actions $A G_{\mathrm{PL}}\left(T X_{\text {acc }} ; T X_{\text {acc }}^{*}\right)$ :

$$
F(P L)=a_{\mathrm{PL} / \mathrm{V}}\left(V-C_{\mathrm{V}}\right)+A G_{\mathrm{PL} / \mathrm{RR}}(P L, R R)-A G_{\mathrm{PL}}\left(T X_{\mathrm{acc}} ; T X_{\mathrm{acc}}^{*}\right),
$$




$$
\begin{gathered}
A G_{\mathrm{PL} / R R}(P L, R R)=I F\left\{R R>C_{\mathrm{RR}} ; 0 ; P L\left[1-\exp \left(-\beta_{\mathrm{PL}} \tau\right)\right]\right\}, \\
A G_{\mathrm{PL} / \mathrm{RR}}\left(T X_{\mathrm{acc}}, T X_{\mathrm{acc}}^{*}\right)=I F\left\{T X_{\mathrm{acc}}<T X_{\mathrm{acc}}^{*} ; 0 ; C_{\mathrm{PL}}\left[1-\exp \left(-\alpha_{\mathrm{PL}} \tau\right)\right]\right\} .
\end{gathered}
$$

In the equation for the volumes of recreational services the sum of effects had the following form:

$$
F(V)=-A G_{\mathrm{V}}(P, E)-A G_{\mathrm{V}}\left(R R, C_{\mathrm{RR}}\right)+a_{\mathrm{V} / \mathrm{D}}\left(D-C_{\mathrm{D}}\right) .
$$

$A G_{V}(P, E)$ agent monitored the profitability level of recreational services constantly comparing the production cost of service $E$ with its market price $P$ and limiting the production when $E>P$ :

$$
A G_{\mathrm{V}}(P, E)=I F\left\{E<P ; 0 ; V(\tau)\left[1-\exp \left(-\alpha_{\mathrm{E}} \tau\right)\right]\right\} .
$$

$A G_{\mathrm{V}}\left(R R, C_{\mathrm{RR}}\right)$ agent limited the production when recreational resource index decreased below its average value:

$$
A G_{\mathrm{V}}(V, R R)=I F\left\{R R>C_{\mathrm{RR}} ; 0 ; V(\tau)\left[1-\exp \left(-\alpha_{\mathrm{RR}} \tau\right)\right]\right\} .
$$

In the equation for the market price of service $P$ the effect of recreational resource $R R$ was taken into account:

$$
F(P)=a_{\mathrm{P} / \mathrm{RR}}\left(R R-C_{\mathrm{RR}}\right),
$$

and in the equation for $E$ production cost - the effect of penalties for pollution $T X$ :

$$
F(E)=a_{\mathrm{E} / \mathrm{TX}}\left(T X-C_{\mathrm{TX}}\right) .
$$

The equation for penalties had the following affecting function:

$$
\begin{aligned}
F(T X) & =a_{\mathrm{TX} / \mathrm{PL}}\left(P L-C_{\mathrm{PL}}\right)+A G_{\mathrm{TX}}\left(P L, P L^{*}\right), \\
A G_{\mathrm{TX}}\left(P L, P L^{*}\right) & =I F\left\{P L<P L^{*} ; 0 ;\left(P L-P L^{*}\right)\left[1-\exp \left(-\alpha_{\mathrm{TX}} \tau\right)\right]\right\} .
\end{aligned}
$$

The amounts of penalties were proportional to the pollution level as long as this level did not exceed the maximum permissible concentration of pollution $P L^{*}$. The agent $A G_{\mathrm{TX}}\left(P L, P L^{*}\right)$ increased the penalty value when this condition was violated.

Economic profitability of recreational services was calculated using the logarithm of relation of $I_{\text {acc }}(t)$ recreation object revenues to $E_{\text {acc }}(t)$ expenses accumulated over $(0 ; t)$ time period:

$$
I_{\mathrm{acc}}=\int_{0}^{t} P^{*} V(t) d t, \quad E_{\mathrm{acc}}=\int_{0}^{t} E(t) V(t) d t, \quad E F=\ln \frac{1+I_{\mathrm{acc}}}{1+\mathrm{E}_{\mathrm{acc}}} .
$$

Each of the model equation was supplemented with the conditions (3).

Computational experiments aimed at testing the model. Numerical implementation of the model was carried out by Euler scheme. In this case, it was adopted the condition $2 \Delta t r_{i} C_{i}=1$ which simplifies the writing of equations and reduces them to the form

$$
u_{i}^{k+1}=2 u_{i}^{k}\left\{1-\frac{1}{2 C_{i}}\left[u_{i}^{k}-F_{i}\left(u_{j}^{k}-C_{j}, A_{i}^{k}\right)\right]\right\} ;
$$




$$
u_{i}^{k}=\operatorname{IF}\left[u_{i}^{k}<0 ; 0 ; \operatorname{IF}\left(u_{i}^{k}>2 C_{i} ; 2 C_{i} ; u_{i}^{k}\right)\right] .
$$

For the convenience of comparing the scenarios of simulated processes, all of them were reduced to a dimensionless form by linear transformations $u_{i} / C_{i}=a_{i j}^{\prime} u_{j} / C_{j}$, in which the dimensionless factors $a_{i j}^{\prime}$ were calculated using formulas (4). Average values were chosen from $(0 ; 10)$ interval of numbers. Mean values were chosen from the interval of numbers $(0 ; 10)$. The results of calculations for 365 time steps are shown in Fig. 2.

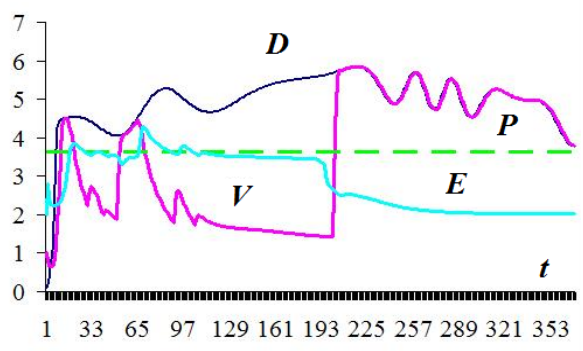

$a$

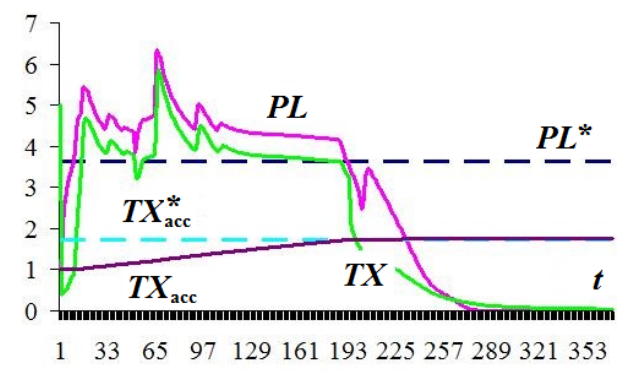

C

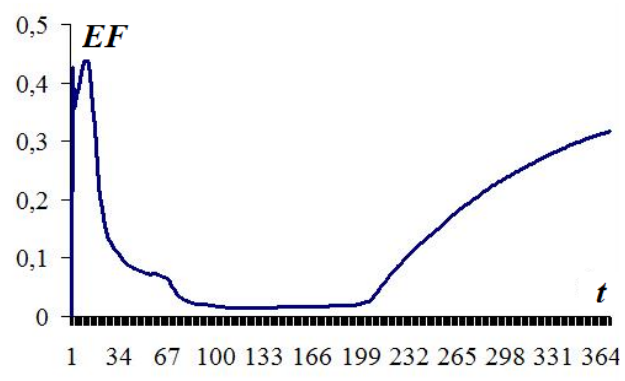

$e$

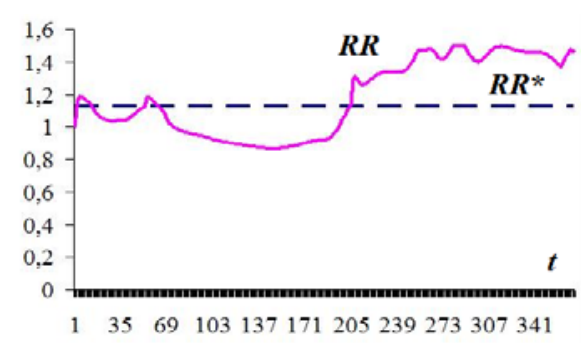

$b$

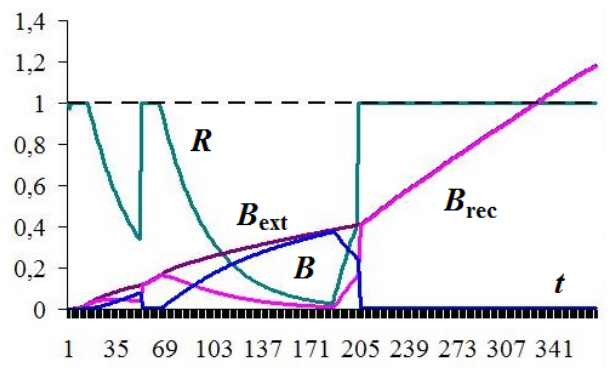

$d$

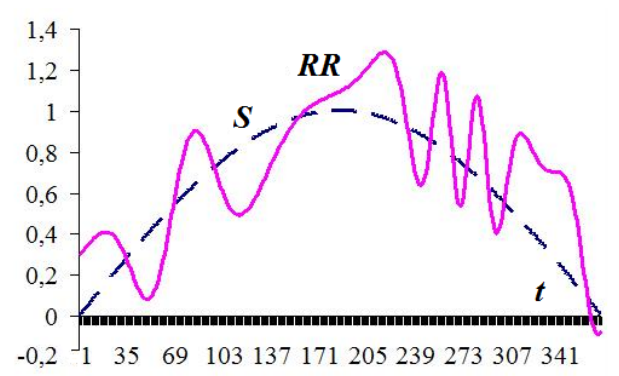

$f$

Fig. 2. Scenarios of ecological and economic processes forecasted by the model affected by seasonal variations of recreational resource $R R(f)$. The graphs $T X_{\text {acc }}$ and $T X_{\text {acc }}^{*}$ are given with factor 0.001 and the graphs $B_{\text {ext }}$ and $B_{\text {rec }}$ - with factor 0.03

In Fig. 2, $a$ the variation of demand $D$ for recreational services $V$ under effect of imitated annual variation $S$ and seasonal variability of the resort recreational attractiveness $R R$ are presented (Fig. 2, $f$ ). In the first half of the year the volumes of 
recreational services significantly lagged behind the demand due to the fact that recreational resource index $R R$ decreased below its average value $R R^{*}$ (Fig. 2, b). The cause of this was high pollution level of environment $P L$ which exceeded the maximum permissible value $P L^{*}$ (Fig. 2, c). Consequently, $A G_{\mathrm{RR}}(E N, I S, E S)$ agent has limited the value of index $R R$ by the value of ecologic safety $E S$ index. Simultaneously, the agent for imposing penalties $A G_{\mathrm{PL} / R \mathrm{R}}(P L, R R)$ set high fines for pollution $T X$ (Fig. 2, c) and production cost of recreational services $E$ turned out to be equal (and sometimes exceeded) their cost $P$ (Fig. 2, $a$ ). In this period of time recreational capacity of the resort decreased as the function $R$ exponentially reduced and the rate of recreational resource recovery $B_{\text {rec }}$ lagged behind the rate of its consumption $B_{\text {ext }}$ (Fig. 2, d). The function of recreational capacity $B$ in the equation (6) additionally reduced the index of recreational resource. As a result of managing the volume of services, the economic profitability $E F$ has sharply decreased and turned out to be close to zero (Fig. 2, e).

Significant changes in the scenarios of environmental-economic processes occurred in the second half of the year when at the $190^{\text {th }}$ experiment step the amount of penalties $T X_{\text {acc }}$ accumulated in the environment cleaning fund reached a value $T X_{\mathrm{acc}}^{*}$ (Fig. 2, c). In this moment of time, $A G_{\mathrm{PL}}\left(T X_{\mathrm{acc}} ; T X_{\mathrm{acc}}^{*}\right)$ agent in the equation for the pollution concentration index turned on the environment purification regime and due to this a dramatic decrease of $P L$ level and $T X$ penalties began (Fig. 2, c). The function $R$ began to rise and this indicated the increase of recreational resource recovery rate (Fig. $2, d$ ). At the $206^{\text {th }}$ step the rates of consumption and reproduction became equal and the volume of recreational resource increased up to the complete satisfaction of the demand (Fig. 2, a). This regime lasted until the end of the experiment which provided a significant increase of economic efficiency of the resort (Fig. 2, e).

\footnotetext{
Application of the model for constructing the spatial-temporal scenarios of recreational resource consumption at the Southern Coast of Crimea zone. In order to carry out this numerical experiment a section of the Southern Coast of Crimea coastal zone (Fig. 3, g) was selected. Previously, in [16], the possibility of constructing the spatial-temporal environmental management scenarios for this area using a slightly different economic model was considered. In our case, the map of the average values of the recreational resource $C_{\mathrm{RR}}$ was constructed by expert assessment of the indices of environmental $C_{\mathrm{EN}}$, infrastructural $C_{\mathrm{IS}}$ and ecological $C_{\mathrm{ES}}$ properties of the region. Important indicator of recreational attractiveness of the area were the data on the number of population because in the considered region the service of holidaymakers is the main source of employment for residents. Such parameters as transport accessibility and ecological condition of the territory and coastal marine area, traditions and the level of resort service for holidaymakers, (etc.) were also taken into account.
} 

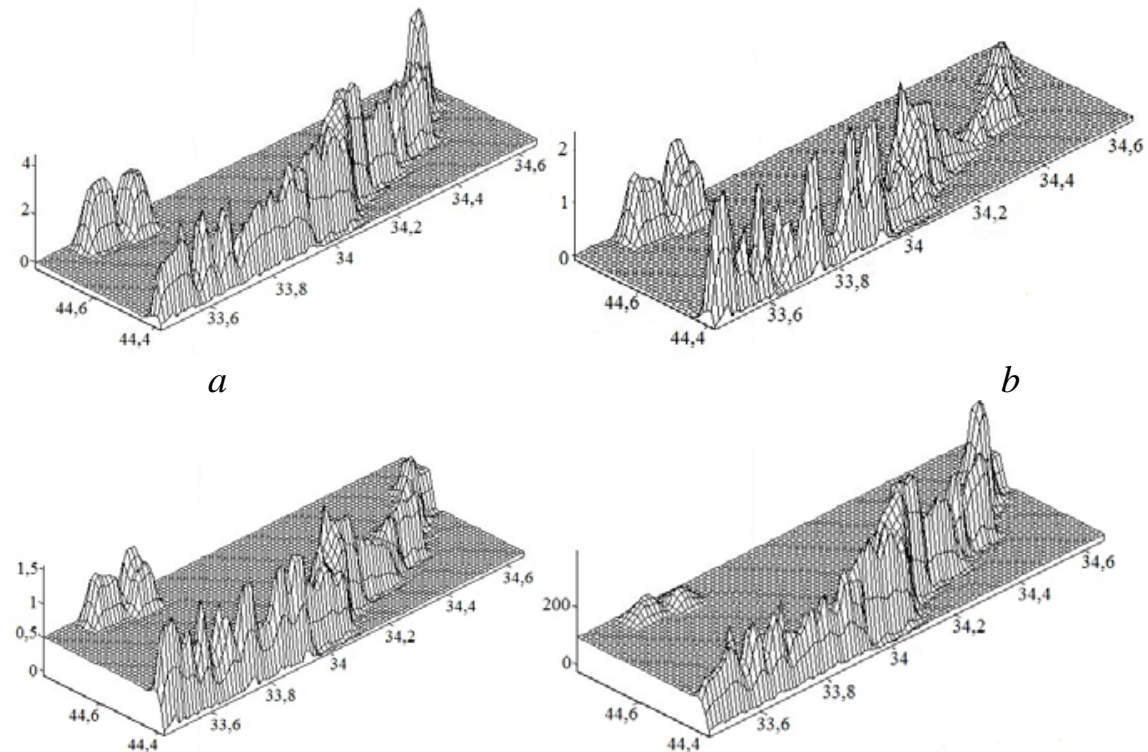

$C$

$d$
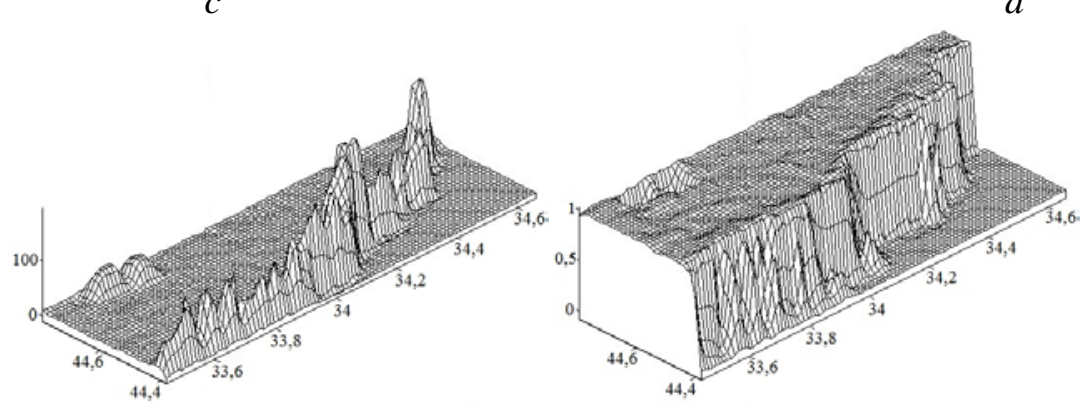

$e$

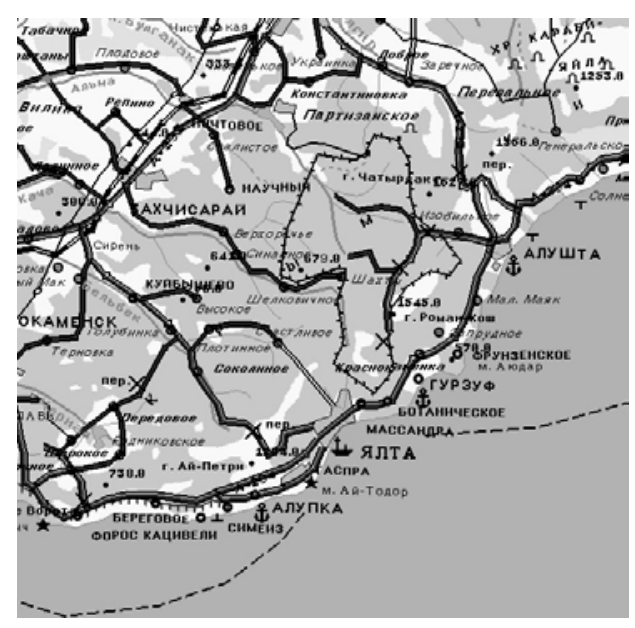

$g$

Fig. 3. Spatial-temporal scenarios of the ecological and economic processes of the Southern Coast of Crimea recreational resource consumption on the $182^{\text {nd }}$ day of a conventional year 
Digital map of the recreational resource contained the values of $C_{\mathrm{RR}}$ index in the nodes of the square grid with $2.5 \mathrm{~km}$ step. A scale of dimensionless points was applied for the index values. Index assessments are interpolated from the settlement location points into the grid nodes that fall into a circle with a center in the settlement and with a radius of 1.5 grid steps. Interpolation weight coefficients were selected to be inversely proportional to the squares of the distances from the settlements to the corresponding nodes of the grid area.

Spatial-temporal scenarios of ecological-economic processes are constructed by applying the model (6)-(12) sequentially in each grid area node. Seasonal variation of recreational attractiveness was simulated using the function $S$ shown in Fig. 2, f. As a result, relief images of scenarios were constructed for each day of a conditional year. The examples of scenarios calculated for $182^{\text {th }}$ day are represented in Fig. 3. In Fig. 3, a D distribution demand for recreational services for this moment of time is shown. The distribution repeats the values of recreational resource index $C_{\mathrm{RR}}$ and provides a general idea of a great contrast between the recreational attractiveness of the maritime part and the rest of the Southern Coast of Crimea coastal zone. Model parameters are selected in such a way that in summer the recreational services are concentrated (except for the Southern Coast of Crimea part of this zone) mainly near Bakhchysarai. The volumes of recreational services that meet the demand are shown in Fig. 3, $b$.

Pollution level scenario is represented in Fig. 3, c. It shows relatively higher pollution levels in the central and eastern parts of the coast in comparison with the western part located near Foros. This is evidenced by the amount of penalties for pollution, as shown in Fig. 3, $d$. Fig. 3, $e$ presents the distribution of the deficiency function of the recreational resource $B$ reproduction. As it was mentioned above, the values of this function, which differ from zero, indicate the violation of recreational resource consumption and reproduction volume balance. This is also confirmed by the scenario of the resource capacity agent $R$ shown in Fig. 3, $f$.

Resource capacity index $R$ sharply decreases along the coast - sea boundary which indicates high pollution level of the beach zone and marine environment.

Conclusion. The analysis of the entire array of the obtained scenarios allowed us to trace spatial-temporal dynamics of resource potential of the Southern Coast of Crimea coastal zone, which is due to the seasonal variability of its recreational attractiveness. Along with the infrastructure and service components, a significant role in the seasonal dynamics of the recreational service volume was played by natural and environmental factors. The decrease in the pollution level of the territory and coastal water area down to permissible controlled limits served as the main criterion for managing the recreational resource of resort objects. The proposed model of ecological-economic system provided a quantitative study of methods for managing this resource. Computational experiments, similar to those considered in this work, make it possible to find such conditions of strict control over the environment pollution level which ensure the profitability of recreational services and the ecological safety of the sea coastal zone. 


\section{REFERENCES}

1. Daly, H. and Farley, J., 2010. Ecological Economics: Principles and Applications. Washington, DC: Island Press, 544 p.

2. Voinov, A., 2008. Systems Science and Modeling for Ecological Economics. New York: Academic Press, $430 \mathrm{p}$.

3. Shogren, J.F., Parkhurst, G.M. and Settle, C., 2003. Integrating Economics and Ecology to Protect Nature on Private Lands: Models, Methods, and Mindsets. Environmental Science \& Policy, [e-journal] 6(3), pp. 233-242. https://doi.org/10.1016/S1462-9011(03)00041-8

4. Crépin, A.-S., Norberg, J. and Mäler, K.-G., 2011. Coupled Economic-Ecological Systems with Slow and Fast Dynamics - Modelling and Analysis Method. Ecological Economics, [e-journal] 70(8), pp. 1448-1458. https://doi.org/10.1016/j.ecolecon.2011.02.004

5. Pearce, D. and Moran, D., 1994. The Economic Value of Biodiversity. London: Earthscan, 172 p. Available at: https://is.gd/S3Wb9Y [Accessed: 30 April 2018].

6. Timchenko, I.E., Igumnova, E.M. and Timchenko, I.I., 2016. Adaptive Balance Models for Environmental-Economic Systems. CreateSpace Independent Publishing Platform, 486 p.

7. Izrael, Y.A., Tsiban, A.V., Ventzel, M.V. and Shigaev, V.V., 1988. Scientific Basis for Ecological Standartization of the Man-Made Effect on Marine Ecosystem are Taken for the Baltic Sea. Oceanology, 28(2), pp. 293-299.

8. Ivanov, V.A., Igumnova, E.M. and Timchenko, I.E., 2012. Coastal Zone Resources Management. Kiev: Academperiodika, 304 p.

9. Ofiara, D.D. and Seneca, J.J., 2001. Economic Losses from Marine Pollution: A Handbook for Assessment. Washington, DC: Island Press, 320 p.

10. Costanza, R., Voinov, A., Boumans, R., Maxwell, T., Villa, F., Wainger, L. and Voinov, H., 2002. Integrated Ecological Economic Modeling of the Patuxent River Watershed, Maryland. Ecological Monographs, [e-journal] 72(2), pp. 203-231. https://doi.org/10.1890/00129615(2002)072[0203:IEEMOT]2.0.CO;2

11. Samhouri, J.F. and Levin, P.S., 2012. Linking Land- and Sea-Based Activities to Risk in Coastal Ecosystems. Biological Conservation, [e-journal] 145(1), pp. 118-129. https://doi.org/10.1016/j.biocon.2011.10.021

12. Bokov, V.A., Timchenko, I.E., Chervanev, I.G. and Rudyk, A.N., 2005. ProstranstvennoVremennoy Analiz v Territorial'nom Menedzhmente [Spatial-Temporal Analysis in Territorial Management]. Simferopol, 183 p.

13. Elofsson, K., Folmer, H. and Grey, I.-M., 2003. Management of Eutrophicated Coastal Ecosystems: a Synopsis of the Literature with Emphasis on Theory and Methodology. Ecological Economics, [e-journal] 47(1), pp. 1-11. https://doi.org/10.1016/j.ecolecon.2003.09.001

14. McCay, B.J. and Jones, P.J.S., 2011. Marine Protected Areas and the Governance of Marine Ecosystems and Fisheries. Conservation Biology, [e-journal] 25(6), pp. 1130-1133. https://doi.org/10.1111/j.1523-1739.2011.01771.x

15. Börger, T., Beaumont, N.J., Pendleton, L., Boyle, K.J., Cooper, P., Fletcher, S., Haab, T., Hanemann, M., Hooper, T.L., 2014. Incorporating Ecosystem Services in Marine Planning: the Role of Valuation. Marine Policy, [e-journal] 46, pp. 161-170. https://doi.org/10.1016/j.marpol.2014.01.019

16. Timchenko, I.E., Igumnova, E.M., Solodova, S.M. and Nikiforov, Yu.I., 2016. Adaptivnaya Model' Rekreatsionnoy Privlekatel'nosti Pribrezhnoy zony Kryma [Adaptive Model of Recreational Attractiveness of The Crimean Coastal Zone]. In: MHI, 2016. Ekologicheskaya Bezopasnost' Pribrezhnoy i Shel'fovoy Zon Morya [Ecological Safety of Coastal and Shelf Zones of Sea]. Sevastopol: ECOSI-Gidrofizika. Iss. 1, pp. 39-47 (in Russian).

17. Timchenko, I.E., Ivashchenko, I.K. and Igumnova, E.M., 2017. Management of EcologicalEconomic Processes of Pollution Accumulation and Assimilation in the Coastal Zone Marine Environment. Physical Oceanography, [e-journal] (1), pp. 68-83. doi:10.22449/1573-160X2017-1-68-83 
18. Timchenko, I.E., Igumnova, E.M. and Timchenko, I.I., 2000. Sistemnyy Menedzhment i ABCTekhnologii Ustoychivogo Razvitiya [System Management and ABC-Technologies of Sustainable Development]. Sevastopol: ECOSI-Gidrofizika, 225 p. (in Russian).

19. Timchenko, I.E. and Igumnova, E.M., 2011. Control over the Ecological-Economic Processes in the Integral Model of the Coastal Zone of the Sea. Physical Oceanography, [e-journal] 21(1), pp. 45-62. https://doi.org/10.1007/s11110-011-9103-9

20. Timchenko, I.E. and Igumnova, E.M., 2004. Prediction of Natural Processes by the Method of Adaptive Balance of Causes. Physical Oceanography, [e-journal] 14(5), pp. 303-312. https://doi.org/10.1007/s11110-005-0011-8

21. Timchenko, I.E. and Igumnova, E.M., 2017. Eco-Economical Models for Recreational Resources Use in the South Coastal Area of the Crimea. In: V. A. Ivanov, E. I. Ignatov, I. S. Kusov, N. N. Milenko, E. V. Yaseneva, E. A Kotel'yanets, eds., 2017. Materialy I Mezhdunarodnogo Ekologicheskogo Foruma V Krymu "Krym - Ekologo-Ekonomicheskii Region. Prostranstvo Noosfernogo Razvitiya”, Sevastopol, 20-24 iyunya 2017 goda [Materials of the I International Ecological Forum in Crimea "Crimea is an Ecological-Economic Region. The Space of Noospheric Development”. Sevastopol, 20-24 June 2017]. Sevastopol: Sevastopol Branch of Moscow State University, pp. 104-108. Available at: http:/sev.msu.ru/wpcontent/uploads/2017/07/SBORNIK_FORUM_2017.543_pdf.pdf [Accessed: 18 July 2018] (in Russian).

About the authors:

Igor E. Timchenko - Head of System Analysis Department, FSBSI MHI (2 Kapitanskaya Str., Sevastopol, 299011, Russian Federation), Dr. Sci. (Phys.-Math.), Professor, Researcher ID: A-86502017, timchenko.syst.analysis@mhi-ras.ru

Ekaterina M. Igumnova - Leading Engineer, Marine Optics and Biophysics Department, FSBSI MHI (2 Kapitanskaya Str., Sevastopol, 299011, Russian Federation)

Igor K. Ivaschenko - Senior Scientist of System Analysis Department, FSBSI MHI (2 Kapitanskaya Str., Sevastopol, 299011, Russian Federation), Dr. Sci. (Econ.)

Julian I. Nikiforov - Leading Engineer, System Analysis Department, FSBSI MHI (2 Kapitanskaya Str., Sevastopol, 299011, Russian Federation)

Contribution of the co-authors:

Igor E. Timchenko - statement of the problem, formula algorithm of Ecological-Economic Model of Managing Recreational Potential

Ekaterina M. Igumnova - construction of conceptual model of the coast-sea system, carrying out the numerical experiments

Igor K. Ivaschenko - discussion of the system economic model

Julian I. Nikiforov - preparing computer programs

All the authors have read and approved the final manuscript.

The authors declare that they have no conflict of interest. 